\title{
СОЦИОВИРТИВНОСТЬ КАК ВИД РЕАЛЬНОСТИ В СОВРЕМЕННОМ ОБРАЗОВАНИИ
}

\author{
Герман Ольга Николаевна, \\ miadegis@mail.ru \\ Томский государственный университет систем управления и радиоэлектроники, \\ Россия, 634050, г. Томск, пр. Ленина, 40
}

Герман Ольга Николаевна, доцент кафедры философии и социологии Томского университета систем управления и радиоэлектроники.

Резкий переход к более активному использованию современных виртуальных технологий в образовании привел к множеству проблем и негативных эффектов, начиная от технической неготовности некоторых вузов к данной реальности, заканчивая психологической напряженностью и снижением качества жизни всех субъектов образования. С целью выявить новые особенности структурных изменений образовательного процесса и обосновать причины возникающих трансформаций, существенно влияющих на качество получаемых дистанционно знаний, было проведено настоящее исследование. В статье предлагается новое понятие «социовиртивность» как новая онтологическая реальность человека. Раскрываются специфические особенности виртуального образа и виртуальной реальности. Объясняются отличия виртуального образа от зеркального. Рассматриваются характерные особенности виртуальной коммуникации. Представлены результаты анкетирования студентов ТУСУРа, в котором приняло участие 122 человека. Анкетирование было направлено на изучение конгруэнтности отношения студентов к первичному опыту перехода на дистанционную форму образования. В результате выявлены позитивные и негативные аспекты погружения в социовиртивное пространство, основные факторы снижения качества образования, заключающиеся в неготовности студентов и педагогов учитывать специфичность виртуальной среды и в отсутствии знаний управления ей и в психологической неготовности к новому формату взаимодействия.

Ключевые слова: Социовиртивность, виртуальная реальность, виртуальное тело, виртуальная социализация, самоидентификация, аутентичность, дистанционное образование, качество знаний, образовательный процесс.

Актуальность темы определяется прежде всего рядом трудностей, связанных с пандемией во всем мире. Трансформации во всех областях жизнедеятельности человека это неизбежный, последовательный, закономерный новый этап в развитии современного общества. Проблема заключается в том, что угроза здоровью ускорила процесс перехода к новому «домашнему» образу жизни. Такой переход приводит к более активному использованию современных виртуальных технологий для достижения поставленных целей. Так, например, одной из сфер, наиболее активно использующих современные виртуальные технологии, является образование. Можно утверждать, что все субъекты, задействованные в образовательном процессе, оказались не готовы к столь стремительным изменениям. Закономерный результат - социальные, психологические напряжения, возникающие как у преподавателей, обучающихся и их родителей, так и со стороны административных органов, участвующих в обеспечении и реализации всех образовательных стандартов. Именно поэтому необходимо прежде всего говорить о социальной, практической и научно-философской значимости исследований, посвященных данной тематике. 
Трудно переоценить значимость данного исследования, позволяющую определить социальные риски и опасности в процессе перехода к смешанной или дистанционной формам обучения, а также значимость качества получаемого образования, существенно влияющего на развитие общества. Роль виртуальной реальности, как в образовании, так и в целом во всех областях социальной жизни, постоянно растет. Следовательно, можно и необходимо говорить о появлении нового важнейшего аспекта человеческого бытия социовиртивной реальности, благодаря которой решается множество социальных проблем современного человека. Особенно обостряется значимость социовиртивности как наиболее успешного средства снижения социальной напряженности, возрастающей в результате появления современных социальных катастроф (пандемии, терроризма). Так, например, Л.С. Набокова в статье «Профессиональное образование в современном мире» утверждает, что благодаря внедрению информационных технологий в вузы появляются более успешные формы обучения, способствующие повышению качества получаемого образования, что приводит к повышению конкурентоспособности специалистов на международном уровне [1].

Для создания более комфортной и эффективно реализующей образовательные стандарты среды особую популярность приобретают создаваемые арт-проекты, виртуальные лаборатории, презентации и гамма-программы, обеспечивающие возможность осуществления как смешанных, так и дистанционных форм трансляции и проверки усвоения необходимых знаний, умений и навыков обучающихся.

Немаловажным аспектом для эффективного (продуктивного) использования современных технологий в образовательном процессе является разработка методологии ускоренного освоения всеми субъектами образовательного процесса технологического инструментария виртуальной среды. Наибольшую проблему представляет собой механизм психологической адаптации, особенно у педагогов «старшего поколения», пытающегося осуществлять образовательный процесс в соответствии с механизмами, действующими при очном обучении. Необходимо осознать, что новые виртуальные платформы требуют кардинально новых подходов к подаче знаний и их оценке.

Социологические, психологические и философские исследования в данной области позволят своевременно осмыслить и выявить решения возникающих проблем социовиртивной реальности. Прогнозы специалистов не однозначны от крайне оптимистичных до экзистенциально катастрофичных. Так, О.А. Донских в статье «Новая нормальность», настаивает на том, что для объективной оценки результатов виртуального обучения необходимо время и говорить об отрицательном или положительном итоге еще рано, но такой резкий переход к дистанционному образованию вряд ли может полноценно заменить очное обучение [2].

Актуальность практической значимости исследования трудно переоценить. Она связана с увеличением времени, проводимым в виртуальной реальности, а значит дома, сидя за компьютером, что не может не сказаться на физическом здоровье, психологическом состоянии всех участников виртуального взаимодействия. Самоорганизация по оздоровлению и компенсации проведенных часов за монитором у большинства населения низкая. Статизация образа жизни приводит к целому комплексу физических заболеваний.

Третий аспект актуализации данного исследования - научно философский. Предметом философского дискурса являются осмысление и обобщение сути происходящих явлений, что дает возможность рационально, объективно, а главное вне зависимости от самих явлений оценить значимость и спрогнозировать последствия возможных вариаций будущего. 
Философский подход к исследованию позволяет раскрыть смысловые трансформации, влияющие в первую очередь на смысловое пространство новой коммуникационной среды, непосредственно связанной с образованием и воспитанием личности. Так, например, в рамках данной статьи будет продемонстрированы специфические отличия виртуальной коммуникационной среды от реальной. Использование образовательных виртуальных платформ меняет характер коммуникации, следовательно, и подход к получению знаний, значимость социальных ролей «преподаватель-студент».

Виртуальные лаборатории, в рамках которых осуществляется образовательный процесс, несомненно, повышают качество усвоения знаний у самоорганизованных и нацеленных на получение знаний (образования) студентов (многократная апробация и повторение пройденного на виртуальном занятии материала), но снижают его у немотивированных и неорганизованных. Таким образом, необходимо говорить о двух важнейших компетенциях виртуального образования (обучения): умение повышать самомотивацию к получению образования и выстраивать самостоятельно логику и методологию освоения дисциплин.

Виртуальный формат предполагает возникновение новой формы гуманизма. Так, например, проводимые экскременты в области химии, биологии, медицины в созданных виртуальных лабораториях повышают частоту и безопасность экспериментов (обучение операционным действиям на виртуальном человеке или животном). Виртуальные технологии менее ресурсозатратны, а следовательно, экологичны.

Таким образом, актуализируется проблема новых этико-эстетических оснований современного научного знания, возникновение новой этико-эстетической иерархии ценностей в социовиртивной реальности как наиболее предпочтительной по отношению к имеющейся в реальности. Решение многих проблем образования: доступность информационных баз, территориальная независимость и доступность консультативных форумов, снятие коммуникационной блокады, мультимедийный планетарный масштаб, доступность формализованных схем оценивания получаемого знания, доступность индивидуального контроля и доступа в личное пространство.

Несмотря на все очевидные достоинства созданного цифрового мира именно в педагогической деятельности, в связи с резким переходом на виртуальные образовательные платформы наиболее очевидными становятся проблемы, которые требуют скорейшего решения.

\section{Обзор проблемы}

За последние десять лет актуальность темы необычайно возросла. Появляется огромное количество статей в самых различных направлениях. В гуманитарной науке исследования по проблеме имеют несколько линий развития:

- Работы К.А. Валиева, Е.Н. Ежовой, В.И. Мартынова, Д.И. Шапиро посвящены анализу понятия «виртуальная реальность».

- М. Кастельс, У. Экко, Д.В. Галкин, Г.П. Отюцкий, Т.Н. Лукиных, Г.В. Можаева, Л.В. Нуралеева, В.А. Ладов, Н.А. Тарабанов и др. занимаются изучением влияния виртуальной реальности на социальные трансформации.

- Е.В. Быстрицкая, Н.П. Лукина, В.А. Сулимов, В. Шелекета, В. Ивахнов, С. Копылов, С.В. Дмитриев, Э. Бонабо и др. рассматривают проблему влияния виртуальности на обесценивание социальных авторитетов и ценностей.

- Проблемам развития когнитивных процессов и образования посвящены работы авторов таких авторов, как К.Г. Фрумкин, Т.Н. Горобец, В.В. Ковалев, Н.В. Азаренов, 
Г.Л. Тульчинский, В.М. Розин. Их проблемное поле охватывает тематики влияния виртуальной реальности на когнитивные свойства человека, сознание и проблемы, связанные с созданием искусственного интеллекта [3]. Проблема изучения влияния виртуальной реальности на образовательный процесс в последнее время весьма актуально, в ней можно выделить следующие линии научного интереса:

- работы, посвященные «лоскутности» виртуальных текстов и виртуального мышления. Авторы подводят к мысли о надвигающейся лингвистической катастрофе (Л.В. Нургалеева, Л.Д. Тюлюпова, Н.А. Мишанкина, Г.М. Маклюэн, В. Михеев, Т.Н. Персикова);

- работы, посвященные проблеме потери носителя памяти (Н.В. Громыко, Ф. Сухейль, О.В. Долженко, О.И. Тарасова, Г.Л. Ильин);

- работы, посвященные методологии дистанционного образования (I. Menter, R. Valeeva, A.A. Kalimullin, L. Yuan, S. Powell, O.B. Михайлов, Я.В. Денисова и т. д.) [4-6];

- работы, посвященные проблемам и принципам проектирования виртуальных сред в образовательном пространстве и психологическим особенностям их восприятия (Л.Р. Нартдинова, М.В. Гуреев, С.В. Крутская, С.С. Елесин, А.В. Фещенко, В.В. Селиванов, Л.Н. Селиваанова, Ф.Р. Загибуллина, Д.Г. Кочергин, Е.Е. Жёрнов) $[7,8]$

- работы, посвященные новому направлению, связанные в трансформацией системы образования в условиях пандемии (И.Р. Гафуров, Г.И. Ибрагимов, А.М. Калимуллин, Т.Б. Алишев, И.А. Алешковский, А.Т. Гаспаришвили, О.В. Крухмалева, Н.П. Нарбут, Н.Е. Савина, S. Krishnamurthy, T. Surma, P. Kirschner) [9-12].

Проблема статьи заключается в том, что неизбежность столь стремительных изменений в образовательном процессе приводит к снижению качества получаемых знаний, несмотря на создаваемые все более совершенные технологии, призванные его повысить.

Цель статьи заключается в том, чтобы выявить новые особенности структурных изменений образовательного процесса и обосновать причины возникающих трансформаций, существенно влияющих на качество получаемых дистанционно знаний.

\section{Методы исследования}

1. Аналитико-синтетический, заключающийся в анализе современной литературы по данной проблеме, для понимания широты исследуемой базы, а также структурирования спектра изучаемых проблем. Обобщение и заключение на основе изучаемой методологической базы позволят объективно определить собственный горизонт исследовательской ниши.

2. Анкетирование. Анкета включала 12 вопросов, направленных на изучение конгруэнтности отношения студентов к первичному опыту перехода на дистанционную форму образования. В исследовании приняли участие студенты ТУСУРа второго курса факультета безопасности в количестве 122 человека.

\section{Результаты исследования}

На первом этапе исследования, для того чтобы понять, как повлияло виртуальное образование на качество знаний всех субъектов образовательного процесса, необходимо рассмотреть, в чем специфика виртуальной реальности. Виртуальная реальность не есть реальность телесная (материальная) и в то же время ни есть идеальная, умопостигаемая реальность. Это пространство образов и знаков, находящееся вне отдельного сознания, 
пребывая в котором, человек как бы находясь в социовиртивной (виртуальная социальность) реальности, остается наедине с собой. Виртуальная реальность обладает свойствами, характерными как для реальной действительности, так и мира идеальных образов. Главной особенностью является ответное действие на запрос пользователя (интерактивность), дающий эффект погружения (трехмерная графика, интерактивные маски...). Главной задачей виртуальной реальности является создание такой системы данных, поступающих из различных источников в сознание человека, чтобы они были удовлетворительны в информационном отношении.

Социовиртивная реальность - универсальный тренажер для отработки матрицы наилучшего действия и в этом смысле универсальная зона комфорта, средство мягкого дистанцирования от других участников виртуальной коммуникации (вроде на связи, но в то же время вне зоны досягаемости, и всегда есть возможность сбежать, сославшись, например, на неполадки в сети).

Социовиртивная реальность - это универсальная среда проявления себя через инобытийные образы. Если личность не проявляет, а лишь воспринимает предлагаемые образы, то это не что иное, как простая трансляция и картинное созерцание. Созерцательное отношение не является условием для появления социовиртивности.

Социовиртивная реальность - это ограниченное представление о себе в образе, созданном программой, а значит, не есть мое истинное воплощение, поэтому не может претендовать на полноценную самоидентификацию в реальности. Это не целостный образа выражения себя, т. е. образ в виртуале не соответствует сущности меня, он (образ) исчерпывается собой, в то время как сущность остается никогда полностью не выраженной ни качественно, ни количественно. Как в зеркале образ меня не соответствует мне, т. к. передает только одну сторону - внешнюю оболочку.

Таким образом, сама по себе виртуальная среда пассивна. От энергии человека зависит сила, порождающая образ, тем самым создавая внутриобразное пространство, т. е. это не самозамыкание. В отличие от зеркала, которое не имеет своего выбора созерцательной активности. Например, «кривляние» перед зеркалом - это выражение воли в образе - виртуал. Тело и его образ не тождественны. Так, например, общение посредством скайпа или других средств не дает проникать в среду внутреннюю или внешнюю, проникнуться атмосферой взаимопереживания общего состояния, т. к. виртуал - зона взаимоизолированности и каждый находится в своей среде.

То же самое можно говорить и о виртуальной аудиальной коммуникации (телефон, конференции в Moodle). В этом смысле самыми ограниченными, в плане полноценного общения, будут все виды письменной речи в виртуале (чаты, сообщения). Аудиообщение - виртуальный слуховой образ, в отличие от чат-сообщения, передающего только информацию и в лучшем случае смайлик - маску. Аудиосообщение содержит больше информации, которая поступает от самого носителя речи: тон, тембр, паузы, - что имплицитно содержит сущностное, а не только образное выражение самого говорящего. В этом смысле такая форма коммуникации воспринимается как более полноценная.

Взаимопонимание - это процесс не только передачи информации и эмоций, это сталкивание с живой энергией, сущностью человека, а следовательно, не является трансляцией. Вот почему так важно, например, в образовательном процессе живое аудиторное общение.

Еще одной особенностью социовиртивной реальности является то, что в отличие от социальной реальности, виртуальная среда связывает всех своих носителей вне зависимости от времени и расстояния на единой виртуальной платформе, но это не живое 
общение людей, это взаимодействие образов. Пример - роман Януша Леона Вишневского «Одиночество в сети». Виртуальный образ не тождественен тебе, а потому его смена не ведет к внутренним трансформациям личности (слабая динамика личностного роста). Например, если сменить стиль одежды со спортивного на классический, то внутреннее напряжение и проявление в поведении сильнее, чем если сменить стиль одежды своего виртуального образа.

Еще необходимо отметить, что виртуальный образ и выбранная социовиртивная роль всегда затмевает реальный, он более предпочтителен, т. к. как это представление о себе, оно наилучшее в твоем понимании. Именно поэтому необходимо признать за виртуальным «Я» онтологический статус.

Социовиртивная роль носит не чисто субъективный характер, но и не материальнопредметный. Именно по этой причине онтологичность социовиртивной роли ограничена ресурсными возможностями. Это ситуация двойного ограничения: телесного - я в моем теле ограничен его возможностями; виртуального, виртуальное тело - образ меня, дистанцированный от моей телесности и от меня. Именно поэтому возникает при виртуальном общении барьер для перехода к более полноценному, реальному общению. Например, даже когда есть возможность, студенты не хотят включать микрофоны и вебкамеры, затрудняются ответить почему.

Таким образом, в виртуальной коммуникации снижается качество диалога, т. к. отсутствуют интуитивное постижение другого, свобода и трансцендентальная активность (энергийный обмен). Так, например, становится невозможным проведение семинаров, т. к. заинтересованность в диалоге снижается. После понравившейся лекции студенты остаются для выяснения каких-либо заинтересовавших лично их моментов, что позволяет углубить содержательно проникновение в смысловое пространство материала. При дистанционной форме возможность задавать вопросы есть, но нет желания это делать. Как правило, вопросы носят формальный характер. Некоторые студенты признаются, что в виртуальной аудитории «неудобно общаться», или говорят: «Ну ... это не то».

Виртуальное образование, активно пропагандируемое в современном мире и актуальное в силу социальных катастроф и угроз (пандемия, терроризм), основанное на информационных технологиях, не может конкурировать с классической аудиторной системой образования, в противном случае мы вынуждены говорить о принципиально новом подходе как к педагогической, так и в целом к системе жизнедеятельности современного общества. Поколение преподавателей - не социовиртивны, поэтому пытаются встраиваться в новую социальность, используя механизмы, применяемые для социализации в реальной действительности.

На втором этапе было проведено исследование среди студентов вуза на предмет их отношения к переходу на дистанционную форму образования. Были выявлены специфические особенности (как положительные, так и отрицательные), повлиявшие на качество коммуникации между педагогами и студентами и на качество получаемых знаний:

1. «Зазеркалье». Как показала практика, большинство студентов, впрочем, как и преподавателей, предпочитают не включать веб-камеры в процессе проведения собраний $-97 \%$. Процент не включающих микрофон несколько ниже - 74 \%, после активных призывов общаться, а не печатать. Что касается лекций, видеокамеры всегда отсутствуют. Несомненным плюсом является возможность писать в чат вопросы, активность в чате высокая и преподаватель может в процессе лекции встраивать ответы, а может их игнорировать. Студенты отмечают тот момент как положительный для понимания лекции $-83 \%$, но при этом предпочли бы в случае выбора занятия в аудитории - $98 \%$, 
говорят о снижение качества восприятия материала - 66 \%, но при этом, затрудняются ответить, почему так - $30 \%$.

Для преподавателя связь со студентами как будто отсутствует. Даже сообщения носят фрагментарный и дистанционный характер, т. е. между вопросом и ответом более длительное время, что разрушает структуру диалога при непосредственном общении (заданный вопрос, требует непосредственного ответа; промежутки ожидания создают напряжение и нежелание продолжать диалог.)

В монологичной речи (лекции) ощущается неполноценность качества преподавания (нарциссизм), т. к. это процесс, зацикленный на самом преподавателе. О самозамкнутом образе мы говорили выше. Другими словами, ведя лекцию, преподаватель видит только свое лицо (как будто читает лекцию своему отражению), реакция аудитории (его отражение) не связано с тем, для кого лекция реально читается, что создает, особенно на первое время, некоторую фрустрацию. Таким образом, лекция превращается не в диалог (глаза студентов и речь преподавателя), а в передачу информации с формальными комментариями.

Таким образом, не возникает в виртуальной аудитории необходимого эмоционального фона рабочей атмосферы для активизации сознания, позволяющего погружаться в смысловые, контекстуальные слои содержания лекции. Типичный ответ студентов на вопрос, снижается ли эмоциональная напряженность в процессе проведения семинара при дистанционной форме обучения? Студенты отвечают: «Да, потому что преподаватель и другие студенты тебя не видят».

2. «Диалог с пустотой». Это явление связано с разрывом преемственности в контактном взаимодействии, разрушением живого коммуникационного пространства, которое приводит к образованию «вакуума» самоидентификации (отождествления себя с группой, пусть и виртуальной). Как следствие, усиливается формализованный подход к образованию и ослабляется содержательный. Как утверждает автор статьи «Дистанционное обучение в российских университетах: “шаг вперед, два шага назад”» О.В. Михайлов, преподаватель в веб-аудитории лишается контроля, обратной связи с группой, в которой работает, что приводит к ослаблению или утрате способности воздействовать на группу, заинтересовывать, контролировать внимание и сосредоточенность, понимание преподаваемого материала [13].

Таким образом, требуется новая аутентичность, при которой формализованные виртуальные образы субъектов коммуникации могут гармонично взаимодействовать. Аутентичность - это качество бытия, существенным образом влияющая на неудовлетворенность получаемых студентами знаний. Именно студенты в первую очередь особо остро переживают отсутствие «живого» общения. Пустота, возникающая без непосредственного общения с преподавателем, влияет на аутентичность, т. к. увеличивает трудности в индивидуальном восприятии, категоризации себя и других, возникших с появлением дифференциации. Все чаще встречаются экзистенциальные кризисные ситуации взаимопонимания (наедине со своим непониманием материала), приводящие к отчуждению от процесса образования, самоограничению. Так, например, на вопрос «Какая из форм образования Вам больше подходит: виртуальная или реальная?» большинство студентов ответили: «Реальная». А на вопрос «Почему?» типичным ответом было: «В кабинете, как и в рабочей обстановке, легче настроиться на познавательную деятельность, а в домашних условиях чаще всего возникает много отвлекающих факторов, препятствующих получению и освоению новых знаний». Эта ситуация приводит к еще одной особенности дистанционного образования. 
3. «Смерть игрегора». Это проблема при дистанционном образовании связана с самоидентификацией. Самоидентификация - это принадлежность к группе, задающей и определяющей единство тебя с ней, целостность, солидарность, создающая парадигмальность в процессе получения и передачи новых знаний. На первое место выходят индивидуальность, или отдельность, переживание устойчивой отрешенности. Дистанционная форма ставит акцент на самообразовании, и если волевая активность не сформирована, мотивация к получению качества знаний снижается.

Опрос показал, что студентов, обладающих самодисциплиной и готовых к самообразованию, достаточно низкий процент. Так, например, порядка 70 \% опрошенных на вопрос о предпочтении проведении занятий с включенной веб-камерой отвечают, что не нуждаются в том, чтобы видеть преподавателя и не хотят, чтобы видели их, тем самым соглашаются на дистанцированность в вопросе формальной передачи знаний, несмотря на то, что в другом вопросе о качестве знаний соглашаются, что оно снижается. Таким образом, можно утверждать, что студенты не осознают причинно-следственной связи между потерей живого общения и качеством получаемых знаний. На вопрос «Почему вы считаете, что качество знаний теряется?» студенты отвечают, что затрудняются ответить. А на предложения и пожелания о том, чтобы не снижался уровень качества знаний, отвечают о необходимости введения большего количество вопросов во время пар от преподавателей. Другими словами, преподаватели также сознательно или несознательно больше формализуют педагогический процесс.

Итак, включаясь в деятельность усваивания нормы поведения, цели и ценности, принципов и формы отношений, качества передаваемых и получаемых знаний, свойственные для дистанционной формы, все субъекты образовательного процесса бессознательно или сознательно переносят навыки диалогового пространства, сформированные реальными отношениями. Таким образом, смена ценностного образца на виртуальный вызывает отрицательную реакцию (осознается как снижение качества получаемых знаний).

4. «Игра теней». Проявляется в формуле «дистанцированность-изолированность», «защищенность-анонимность». Данный феномен связан как минимум с двумя психологическими особенностями, которые ориентированы на создание максимально комфортного существования в социовиртивности:

1) страх не быть зрелищным (за спины соседей не спрячешься), все как на первой парте. Следовательно, в любое время преподаватель на тебе может сосредоточить внимание, поэтому предпочтение отдается форме работы с выключенной веб-камерой (я тут, но меня как бы нет, до тех пор, пока я не захочу проявить активность);

2) включить видеосвязь, значит поделиться интимной информацией о личной среде, куда я впускаю самых близких. Формализованный подход не располагает к раскрытию личной информации (как в квартире, как я выгляжу дома). Поэтому на просьбу включить видеосвязь студенты, как правило, отвечают, что не позволяют это сделать технические возможности.

Несомненным плюсом является осознанность собственной роли в процессе образования. Студенты отмечают, что, только работая удаленно, понимаешь, что все зависит от тебя. При дистанционной форме образования удобно самостоятельно регулировать степень погруженности в материал, весь даваемый материал можно восстановить в удобном месте нужное количество раз. Ты находишься не в стрессовой ситуации, лишен нагрузки, связанной с социальным дискомфортом (как со стороны преподавателя, так и студентов). 
5. «Бегство от реальности». Это явление связано с усилением степени самообразования. Дистанция лишает подсказок, одобрений при непосредственном решении образовательных задач, «человеческих лайфхаков», позволяющих сократить и направить на путь, помогающий быстро проникнуть в материал. Надо отметить, что многие студенты оценивают «дистант» как психологически спокойную форму, т. к. нет давления со стороны преподавателя, снижается напряжение и панические атаки от невозможности найти быстро правильный ответ. Дистанция дает возможность в любой момент незаметно исчезнуть или появиться - это плюс «никому не мешаю». Написать ответ при личном обращении «не знаю», по мнению студента, гораздо проще, чем то же самое сказать в аудитории, глядя в глаза. Так же как написать отказ с помощью смс проще, чем позвонить или в личной беседе.

Так, на вопрос «Снижается ли эмоциональная напряженность в процессе проведения семинара при дистанционной форме обучения?» студент отвечает: «Да», объясняя, что при такой форме «Собеседник тебя не видит, при этом ты находишься в спокойной домашней обстановке. Иными словами, домашняя обстановка - защита, буфер от психологического давления. Крайнее напряжение возникает в сессию, поэтому на вопрос «Какую форму проведения экзамена/зачета Вы бы предпочли: дистанционную или в аудитории?» фактически все студенты ответили: «Дистанционную, потому что перед экзаменом сильно волнуешься, тем более, когда вы по одному заходите в кабинет для сдачи экзамена/зачета, чувствуется нарастающее напряжение». Несмотря на то, что в виртуальной аудитории это тоже может быть беседа с преподавателем, реальная ситуация «в аудитории» указывает, на невозможность спрятаться.

6. «Всегда на связи». Снижается напряжение «упущенного времени». При дистанционной форме любой студент в любое время может связаться для решения вопросов с любым преподавателем и нет необходимости специально ехать в университет и обращаться на кафедру за помощью. Многими преподавателями это воспринимается как нарушение личных границ. Закон «бумеранга» - не работает. (Например, появление задолженности сопряжено не только с образованием, но и формальными трудностями, готовностью преподавателя решать твои проблемы.) Снят механизм вовлечения в организацию учебного процесса.

Еще один аспект этого явления - доступность необходимого минимума материала. Bce выложено в Moodle. Снижается активность в поиске дополнительной информации, сравнения самостоятельно найденного материала в различных источниках. Однако онлайн-платформа предполагает осуществление более полноценного контроля, хотя и формального над учащимися и преподавателями. Цифровая запись предполагает возможность проследить тенденции осуществления образовательного процесса более легко, несколькими нажатиями клавиш составить портрет успеваемости по всем предметам. Это может способствовать развитию самостоятельного подхода в образовании, сформировав индивидуальные векторы осуществления элементов образовательного процесса. Но в то же время и воспринимается как негативно оцениваемая перспектива. Формирование привычки «работать и жить под контролем» всех субъектов образовательного процесса создает напряжение «без права на ошибку», т. к. все фиксируется и может быть использовано против нарушителя. Потеря приватности и сакральности приводит к лишению личностного образовательного пространства, что формализует и лишает живой энергии образовательный процесс.

7. Формализация. В виртуальной преподавательской деятельности меняется роль педагога. Если в реальном режиме преподаватель - собеседник, цель которого найти язык объяснения, то в виртуале - акцент ставится на формировании грамотной выборки 
материалов, необходимых для понимания и отсылки студентов к этим источникам. Для самого преподавателя такой подход даже предпочтительней (выложил материал, провел тест-опрос), создается иллюзия снятия ответственности. Преподаватель - транслятор знаний, а не учитель. Так, на вопрос «Снижается или повышается концентрация внимания и интеллектуальная активность в процессе проведения семинара при самостоятельном изучении выложенного материала?» ответ 89 \% опрошенных: «Снижается. Не хватает атмосферы работы, чувствуется свободное интернет обучение, а не университетское». Студенты говорят о том, что восприятие материала идет хуже, не достаточно глубоко проникают в содержание материала, когда занимаются дистанционно.

Виртуальная среда формирует новые установки:

1. Доступность виртуальной информационной среды снижает активность расширять информационный портал, снимая активность искать альтернативную или дополнительную информацию, как следствие - усреднение даваемых ответов и отсутствие личной контекстуальности, следовательно, происходит сужение горизонта интерпретационных вариаций, ограниченность и стандартизация. На вопрос «Возникают ли трудности в более глубоком понимании при дистанционном образовании?» фактически все студенты ответили утвердительно. А на вопрос «Чаще ли при дистанционном образовании в процессе обсуждения темы Вы обращаетесь к интернет-ресурсам («гугл рулит!») в поиске ответа на вопрос?» ответ был либо «Затрудняюсь ответить», либо «Да».

2. Возможности возросли - мотивация упала. Отсутствие на портале информации вызывает фрустрацию и приводит к отсутствию поиска материала из других источников.

3. Отсутствие необходимости регулярной активности в поиске ответа на соответствие и расширение горизонта знания приводит не к самостоятельности решения, а к картинному восприятию материала. Поскольку все готовятся по одному источнику, нет обращения к дополнительным источникам, ограничиваясь имеющимся материалом, то не активизируется творческое мышление, являющееся результатом соответствия различных контекстов.

4. Отсутствие критичности приводит к преобладанию описательного воспроизведения материала, снижается коэффициент затраченных усилий. Все это влияет на качество получаемых знаний. Самое главное - отучают критично мыслить, самостоятельно создавать смысловые конструкты [9].

5. «Ширма сознания». И последний момент, на который хотелось обратить внимание: в социовиртивном пространстве снижаются морально-эстетические требования к процессу коммуникации. Другими словами, внешний вид и параллельно выполняемые дела (леплю пельмени и читаю лекцию) теряют аксиологическую значимость. Самый распространенный ответ на вопрос «Почему не используете все технические возможности (предпочитаете писать)?» - «Не работает камера или нет микрофона», но они появляются у всех, когда выставляются жесткие требования обязательности видео-аудиосвязи. Надо отметить еще один момент. Виртуальное тело - не социальное и не физическое. Это просто образ, маскарад. Так, например, молчать, не зная ответа проще, чем смотреть в глаза преподавателю. Проще написать, что не готов, чем сказать в глаза.

На вопрос «В виртуальной форме проведения занятий Вам: проще говорить, писать?» дан ответ «Писать, потому что при ответе на вопрос ты можешь подумать, что написать, и при этом не будет слышно посторонних домашних шумов». При этом на вопрос «Возникает ли в дистанционной форме обучения ощущение неполноценной беседы?» ответ всегда однозначный - «Да, но затрудняюсь ответить почему».

Со стороны преподавателей требования усиливаются. Записанная видеолекция носит более сложный конструкт, более сильное психологическое напряжение. Несмотря на 
то, что преподаватель, занимающийся созданием профессиональных видеолекций, находится в «тренде», он уже не просто лектор, он модельер самопрезентации. Поскольку при аудиторных занятиях критерии самопрезентации условны, трансформируемы в процессе ведения лекции, то формат видео статичен и может подлежать разбору и оценке. Данную проблему также исследуют В.Б. Никишина, А.А. Кузнецова [14].

По результатам исследования установлено, что как со стороны педагогического состава, так и со стороны студенческой аудитории проблема снижения качества получаемых знаний стоит на первом месте. Но со стороны преподавательского состава наблюдается более глубокая рефлексия относительно причин и следствий претерпеваемых изменений. Студенты не могут отвечать на вопросы о причинах переживаний, связанных с потерей носителя знаний и замены его на виртуальный образ, не могут оценить несостоятельность и противоречивость собственных позиций относительно аудио-видео-образа, воспринимают общение посредством чата как ограниченную форму общения (лоскутность сознания и невозможность работать с большими объемами информации), не осознают необходимости веб-контакта с преподавателем и даже негативно его оценивают. Анализ анкетных данных привел к следящим выводам:

1. Зеркальная форма преподавания снижает эмоциональную напряженность, повышая уровень нарциссизма, превращая процесс преподавания в самопроговаривание материала («для себя»), что не способствует к активизации лектора на проблемное изложения материала, а скорее склоняет его к пассивному и описательному.

2. Пустотность или отсутствие живого собеседника формализует общение и затрудняет вхождение в необходимое образовательное состояние, снижает мотивацию и ответственность за непосредственный ответ, проявляется в молчании на вопрос преподавателя и отсутствии переживаний по этому поводу («универсальная игра в прятки»). Со стороны преподавателей воспринимается как равнодушие и безучастие (фактически неуважение), а со стороны студентов не осознается как проблема.

3. Отсутствие игрегора - духа рабочей атмосферы. Не позволяет преподавателю своевременно оценить и контролировать степень понимания излагаемого материала группой в целом. Отсутствие рабочей атмосферы снижает контекстуальность, степень проникновенности, содержательного углубления в материал. Со стороны преподавателей воспринимается как негативное явление, ухудшающее качество получаемых знаний, со стороны студентов - как более комфортное, удобное и, несмотря на недостатки, все равно предпочтительное.

4. Дистанцированность воспринимается студентами как защищенность. Оценивается как снижение психологической напряженности, стимулирующее волевые аспекты при осуществлении образовательного процесса. Преподаватели склоняются к позиции, что в такой ситуации усиливается отчужденность, а следовательно, и активность сознания в процессе получаемых знаний. Со стороны студентов данная ситуация воспринимается как более легкая, а потому предпочтительная.

5. Лишаясь «лайфхаков» преподавателя, студент расфокусирован, теряет объективность оценочных ориентиров в самообразовании, роль которого при дистанционной форме усиливается.

6. Доступность образовательной среды оценивается преподавателями как посягательство на личное пространство, в то время как студенты утверждают, что это несомненный плюс, т. к. предполагает возможность в любой момент получить необходимую консультацию.

7. Дистанционная форма образования формализует процесс получения знаний, снимает критичность оценивания результатов. Активизируется репродуктивный (конвергентный) тип мышления, а не творческий (дивергентный). 
8. Происходит снижение морально-эстетических требований, которое приводит к безответственному отношению к процессу обучения в целом, что непосредственно влияет на успеваемость.

Общий вывод: таким образом, было установлено, что в той форме, в которой осуществляется современная педагогическая деятельность, виртуальная форма не может претендовать на полноценное замещение аудиторных занятий. Ни студенты, ни педагоги в полной мере не осознают и не могут соответствовать специфическим требованиям, диктуемым дистанционной формой, пытаясь вписать старые подходы и используя средства, которые были приемлемы для очной формы обучения. Требуется более длительное время для адаптации и выстраивания нового механизма преподавательской деятельности, предполагающей изменение социальных ролей всех субъектов образовательного процесса. Необходимо создание новых критериев, отвечающих требованиям виртуальной коммуникационной среды. И главное - необходимо осмысление новых форм личностного роста, проблем самоидентификации, аутентичности, виртуальной телесности, социализации, как новой формы бытия человека. Онтологический статус человека претерпевает существенные трансформации, необходимо осмысление новых экзистенциалов человеческого бытия.

\section{Заключение}

При переходе на дистанционное образование ни педагоги, ни студенты не выстраивают социовиртивную реальность с учетом ее специфических особенностей. Происходит попытка отождествить или встроить законы коммуникационного действия в реальности под виртуальную среду. Не наработаны привычки, связи, механизмы, позволяющие созданную альтернативную форму осуществления образовательного процесса по средствам виртуальных технологий использовать для получения образования, не теряя качественно ценных моментов, наличествующих в реальной форме. Проблема социовиртивности актуальна и требует рассмотрения ее и по отношению к другим аспектам бытия человека в виртуальной реальности.

\section{СПИСОК ЛИТЕРАТУРЫ}

1. Носов Н.А. Виртуальная реальность (виртуальная философия, виртуальная психология) // Вопросы философии. - 1999. - № 10. - С. 152-164.

2. Донских О.А. Новая нормальность? // Высшее образование в России. - 2020. - Т. 29, № 10. - С. $56-64$.

3. Тульчинский Г.Л. Цифровая трансформация образования: вызовы высшей школе // Философские науки. - 2017. - № 6. - C. 121-136.

4. Menter I., Valeeva R., Kalimullin A. A tale of two countries-forty years on: politics and teacher education in Russia and England // European Journal of Teacher Education. - 2017. - № 40 (5). - P. 616-629. DOI: https://doi.org/10.1080/02619 768.2017.1385060

5. Yuan L., Powell S. MOOCs and disruptive innovation: implications for higher education // eLearning Papers, In-depth. - 2013. - V. 33. - № 2. - P. 1-7.

6. Михайлов О.В., Денисова Я.В. Дистанционное обучение в российских университетах: «шаг вперед, два шага назад» // Высшее образование в России. - 2020. - Т. 29, № 10. - С. 65-69.

7. Елесин С.С., Фещенко А.В. Виртуальная реальность в образовании: сомнения и надежды // Гуманитарная информатика. - 2016. - № 10. - С. 109-114.

8. Кочергин Д.Г., Жёрнов Е.Е. Опыт цифровизации высшего образования в США // Профессиональное образование в России и за рубежом. - 2019. - № 2 (34). - С. 12-23.

9. Трансформация обучения в высшей школе во время пандемии: болевые точки / И.Р. Гафуров, Г.И. Ибрагимов, А.М. Калимуллин, Т.Б. Алишев // Высшее образование в России. - 2020. - Т. 29, № 10. - С. $101-112$.

10. Студенты вузов России о дистанционном обучении: оценка и возможности / И.А. Алешковский, А.Т. Гаспаришвили, О.В. Крухмалева, Н.П. Нарбут, Н.Е. Савина // Высшее образование в России. - 2020. T. 29, № 10. - C. 86-100. DOI: https://doi.org/10.31992/0869-3617-2020-29-10-86-100. 
11. Krishnamurthy S. The future of business education: a commentary in the shadow of the Covid-19 pandemic // Journal of Business Research. - 2020. - V. 117. - P. 1-5. DOI: https:// doi.org/10.1016/j.jbusres.2020.05.034

12. Surma T., Kirschner P. Technology enhanced distance learning should not forget how learning happens // Computers in Human Behavior. - 2020. - V. 110. September. DOI: https://doi.org/10.1016/j.chb.2020.106390

13. Набокова Л.С., Загибулина Ф.Р. Перспективы внедрения технологий дополненной и виртуальной реальности в сферу образовательного процесса высшей школы // Профессиональное образование в современном мире. - 2019. - Т. 9. - № 2. - С. 2710-2719.

14. Кузнецова А.А., Никишина В.Б. Видеолекция как самопрезентация преподавателя вуза в условиях электронного образовательного пространства // Высшее образование в России. 2018. - Т. 27, № 4. - С. 149-155.

Поступила 09.09.2020 2. 
UDC 37:004

\title{
SOCIOVIRTIVITY AS A KIND OF REALITY IN MODERN EDUCATION
}

\author{
Olga N. German, \\ miadegis@mail.ru \\ Tomsk State University of Control Systems and Radioelectronics, \\ 40, Lenin avenue, Tomsk, 634050, Russia
}

Olga N. German, associate professor, Tomsk University of Control Systems and Radioelectronics.

A sharp transition to more active use of modern virtual technologies in education has led to many problems and negative effects, ranging from the technical unpreparedness of some universities for this reality, ending with psychological tension and a decrease in the quality of life of all subjects of education. In order to identify new features of structural changes in the educational process and substantiate the causes of emerging transformations that significantly affect the quality of knowledge acquired remotely, this study was conducted. The article proposes a new concept of «sociovirtuality» as a new ontological reality of a person. The specific features of the virtual image and virtual reality in contrast to social reality are revealed. The paper explains the differences between a virtual image and a mirror image. The characteristic features of virtual communication are considered. The results of a survey of TUSUR students, in which 122 people took part, are presented. The survey was aimed at studying the congruence of students' attitudes towards the primary experience of transition to distance education. As a result, the authors revealed the positive and negative aspects of immersion in the sociovirtual space, the main factors of education quality decrease, consisting in unwillingness of students and teachers to take into account the specificity of the virtual environment, in the absence of knowledge of how to manage it and in the psychological unwillingness to a new format of interaction.

Key words: Sociovirtuality, virtual reality, virtual body, virtual socialization, self-identification, authenticity, distance education, quality of knowledge, educational process.

\section{REFERENCES}

1. Nosov N.A. Virtualnaya realnost (virtualnaya filosofiya, virtualnaya psikhologiya) [Virtual reality (virtual philosophy, virtual psychology)]. Voprosy filosofii, 1999, no. 10, pp. 152-164.

2. Donskikh O.A. Novaya normalnost? [New normalcy?]. Vysshee obrazovanie v Rossii, 2020, vol. 29, no. 10, pp. 56-64.

3. Tulchinskiy G.L. Tsifrovaya transformatsiya obrazovaniya: vyzovy vysshey shkole [Digital transformation of education: challenges to higher education]. Filosofskie nauki, 2017, no. 6, pp. 121-136.

4. Menter I., Valeeva R., Kalimullin A. A tale of two countries-forty years on: politics and teacher education in Russia and England. European Journal of Teacher Education, 2017, no. 40 (5), pp. 616-629. DOI: https://doi.org/10.1080/02619 768.2017.1385060

5. Yuan L., Powell S. MOOCs and disruptive innovation: Implications for higher education. eLearning Papers, In-depth, 2013, vol. 33, no. 2, pp. 1-7.

6. Mikhaylov O.V., Denisova Ya.V. Distantsionnoe obuchenie v rossiyskikh universitetakh: «shag vpered, dva shaga nazad» [Distance learning in Russian universities: «one step forward, two steps back»]. Vysshee obrazovanie v Rossii, 2020, vol. 29, no. 10, pp. 65-69.

7. Elesin S.S., Feshchenko A.V. Virtualnaya realnost $\mathrm{v}$ obrazovanii: somneniya i nadezhdy [Virtual reality in education: doubts and hopes]. Gumanitarnaya informatika, 2016, no. 10, pp. 109-114.

8. Kochergin D.G., Zhernov E.E. Opyt tsifrovizatsii vysshego obrazovaniya v SShA [Experience of digitalization of higher education in the USA]. Professionalnoe obrazovanie v Rossii i za rubezhom, 2019, no. 2 (34), pp. 12-23.

9. Gafurov I.R., Ibragimov G.I., Kalimullin A.M., Alishev T.B. Transformatsiya obucheniya v vysshey shkole vo vremya pandemii: bolevye tochki [Transformation of education in higher education during a pandemic: pain points]. Vysshee obrazovanie v Rossii, 2020, vol. 29, no. 10, pp. 101-112. 
10. Aleshkovskiy I.A., Gasparishvili A.T., Krukhmaleva O.V., Narbut N.P., Savina N.E. Studenty vuzov Rossii o distantsionnom obuchenii: otsenka i vozmozhnosti [Students of Russian universities on distance learning: assessment and opportunities]. Vysshee obrazovaniye v Rossii, 2020, vol. 29, no. 10, pp. 86-100. DOI: https://doi.org/10.31992/0869-3617-2020-29-10-86-100.

11. Krishnamurthy S. The future of business education: a commentary in the shadow of the Covid-19 pandemic. Journal of Business Research, 2020, vol. 117, pp. 1-5. DOI: https:// doi.org/10.1016/j.jbusres.2020.05.034

12. Surma T., Kirschner P. Technology enhanced distance learning should not forget how learning happens. Computers in Human Behavior, 2020, vol. 110, September. DOI: https://doi.org/10.1016/j.chb.2020.106390

13. Nabokova L.S., Zagibulina F.R. Perspektivy vnedreniya tekhnologiy dopolnennoy i virtualnoy realnosti v sferu obrazovatelnogo protsessa vysshey shkoly [Prospects for the introduction of augmented and virtual reality technologies in the sphere of the educational process of higher education]. Professionalnoe obrazovanie v sovremennom mire, 2019, vol. 9, no. 2, pp. 2710-2719.

14. Kuznetsova A.A., Nikishina V.B. Videolektsiya kak samoprezentatsiya prepodavatelya vuza $\mathrm{v}$ usloviyakh elektronnogo obrazovatelnogo prostranstva [Video lecture as a self-presentation of a university teacher in an electronic educational space]. Vysshee obrazovaniye v Rossii, 2018, vol. 27, no. 4, pp. 149-155.

Received: 9 September 2020. 